\title{
Article \\ Co-Expression of Nogo-A in Dopaminergic Neurons of the Human Substantia Nigra Pars Compacta Is Reduced in Parkinson's Disease
}

\author{
Gian-Carlo Eyer ${ }^{1}$, Stefano Di Santo ${ }^{1}{ }^{\mathbb{D}}$, Ekkehard Hewer ${ }^{2,3}$, Lukas Andereggen ${ }^{1,4}{ }^{(D)}$, Stefanie Seiler ${ }^{1}$ \\ and Hans Rudolf Widmer ${ }^{1, *}$
}

1 Neurocenter and Program for Regenerative Neuroscience, Department of Neurosurgery, Inselspital, Bern University Hospital, University of Bern, 3010 Bern, Switzerland; gian-carlo.eyer@students.unibe.ch (G.-C.E.); stefano.disanto@insel.ch (S.D.S.); lukas.andereggen@ksa.ch (L.A.); stefanieseiler7@hotmail.com (S.S.)

2 Institute of Pathology, University of Bern, 3010 Bern, Switzerland; Ekkehard.Hewer@unil.ch

3 Institute of Pathology, University of Lausanne, 1011 Lausanne, Switzerland

4 Department of Neurosurgery, Kantonsspital Aarau, 5001 Aarau, Switzerland

* Correspondence: hansrudolf.widmer@insel.ch; Tel.: +41-031-632-2770

\section{check for}

updates

Citation: Eyer, G.-C.; Di Santo, S.; Hewer, E.; Andereggen, L.; Seiler, S.; Widmer, H.R. Co-Expression of Nogo-A in Dopaminergic Neurons of the Human Substantia Nigra Pars Compacta Is Reduced in Parkinson's Disease. Cells 2021, 10, 3368. https://doi.org/10.3390/ cells10123368

Academic Editors: Wolfgang Jost and Alexander E. Kalyuzhny

Received: 18 October 2021

Accepted: 27 November 2021

Published: 30 November 2021

Publisher's Note: MDPI stays neutral with regard to jurisdictional claims in published maps and institutional affiliations.

Copyright: (c) 2021 by the authors. Licensee MDPI, Basel, Switzerland. This article is an open access article distributed under the terms and conditions of the Creative Commons Attribution (CC BY) license (https:/ / creativecommons.org/licenses/by/ $4.0 /)$.

\begin{abstract}
Parkinson's disease is mainly characterized by a progressive loss of dopaminergic neurons in the substantia nigra pars compacta. Together with the small number, the high vulnerability of the dopaminergic neurons is a major pathogenic culprit of Parkinson's disease. Our previous findings of a higher survival of dopaminergic neurons in the substantia nigra co-expressing Nogo-A in an animal model of Parkinson's disease suggested that Nogo-A may be associated with dopaminergic neurons resilience against Parkinson's disease neurodegeneration. In the present study, we have addressed the expression of Nogo-A in the dopaminergic neurons in the substantia nigra in postmortem specimens of diseased and non-diseased subjects of different ages. For this purpose, in a collaborative effort we developed a tissue micro array (TMA) that allows for simultaneous staining of many samples in a single run. Interestingly, and in contrast to the observations gathered during normal aging and in the animal model of Parkinson's disease, increasing age was significantly associated with a lower co-expression of Nogo-A in nigral dopaminergic neurons of patients with Parkinson's disease. In sum, while Nogo-A expression in dopaminergic neurons is higher with increasing age, the opposite is the case in Parkinson's disease. These observations suggest that Nogo-A might play a substantial role in the vulnerability of dopaminergic neurons in Parkinson's disease.
\end{abstract}

Keywords: Nogo-A; Parkinson's disease; tyrosine hydroxylase; substantia nigra pars compacta; human; immunofluorescence

\section{Introduction}

Parkinson's Disease (PD) is the second most frequent neurodegenerative disorder, and among this category it is the fastest growing source of disability [1]. PD is age-related and typically diagnosed by the presence of motor deficits, including resting tremor, rigidity, bradykinesia and postural imbalance [2]. The primary trigger of the motor symptoms of PD consists in the depletion of dopamine in the striatum, resulting from a progressive loss of mesencephalic dopaminergic (DA) neurons projecting from the substantia nigra pars compacta $(\mathrm{SNc})$. Currently there are no effective strategies to arrest the progression of PD [3].

The pathophysiology of PD is complex and relies on dysfunctions of different types of neuronal cells, circuits and structures of the central and autonomic nervous system. In this scenario, however, the death of nigral DA neurons is a crucial stage. There is evidence that DA neurons are particularly vulnerable [4]. Factors such as the extensive arborization and length of the axons, the relatively low cytosolic calcium buffering capacity and the potential 
toxicity of dopamine might predispose the DA neurons to dysfunctions. Endogenous and exogenous toxic insults, such as oxidative stress, accumulation of misfolded protein, inflammation and environmental toxins are the major causes of impairment of DA neuron viability. At the same time, it has been reported that subpopulations of DA neurons are more resilient to neurodegeneration [5-7]. Furthermore, a gradual and moderate decrease in DA neuron densities in the SNc appears to be a physiological process associated with aging, which seems to differ in some aspects to the neurodegenerative process occurring in PD [8-11]. These observations underscore the importance of a thorough comprehension of the determinants of DA neuron viability; a better characterization of DA neurons and in particular those spared during aging and in PD could help to unravel the mechanisms of neurodegeneration and identify new targets to modify its progression.

In our previous studies, we have hypothesized that the myelin-associated protein and potent inhibitor of neurite outgrowth Nogo-A (rericulon-4) might play a role in the DA neuron viability. Since the original description in the late 1980s, the array of functions of Nogo-A has widened [12]. It is now clear that different cell types in the neuronal tissue express Nogo-A besides oligodendrocytes, including neurons, endothelial cells, microglia $[13,14]$. Correspondingly, Nogo-A acts as modulator of neuronal circuit plasticity, angiogenesis, stem cell maturation and immune response [15,16]. Ourselves and others have also described that Nogo-A is expressed in cultured DA cells as well as in neurons in the SNc of adult rats [17-19]; a subpopulation of these cells were identified as projection neurons [12]. Importantly, we have previously reported an increased density of DA neurons co-expressing Nogo-A in an animal model of PD [18]. Compelling evidence indicates that Nogo-A signaling is involved in neuronal dysfunction and repair mechanisms in different neurodegenerative conditions, including spinal cord injury, ALS, Alzheimer's and stroke [20-23] as well as psychiatric disorders such as schizophrenia [24]. Several studies have shown that the suppression of the Nogo-A-dependent inhibitory signals enhance neuronal plasticity and sprouting in damaged tissue as well as in neuronal transplantation settings. However, it is clear that a deep understanding of the changes occurring in damaged and aging neuronal tissue is essential to shape a promising therapeutic concept into safe and effective interventions [25]. In this context, the elucidation of Nogo-A expression might be relevant to address the pathogenesis of PD. However, the expression of Nogo-A in human SNc has not been reported yet. Hence, in the present study we aimed to characterize the expression of Nogo-A in DA neurons in the SNc obtained from PD and non-diseased subjects using a tissue micro array (TMA) platform. We have found a fairly abundant Nogo-A expression in human adult SNc and observed striking differences in the $\mathrm{TH} /$ Nogo-A co-localization rate in relation to age in the two populations. These results might advance our knowledge on the vulnerability of DA neurons.

\section{Materials and Methods}

\subsection{Construction of the Human Substantia Nigra Pars Compacta TMA}

The present study was performed with approval of the ethics committee of the Canton of Bern (KEK the 200/14). The TMAs were produced as described in detail previously [26,27]. In brief: stored human midbrain paraffin embedded tissue was obtained. Hematoxylin-eosin (HE) stained slides were scanned and photographed using a Pannoramic 250 (3DHistech). Ekkehard Hewer annotated areas in the left and right SNc suitable for the TMA (Figure 1A). These areas that were $2 \mathrm{~mm}$ in diameter were then punched out of the donor paraffin block and mounted onto a recipient block. TMA blocks presented with approximately 40 samples in which the first three samples included non-neuronal tissues, i.e., from kidney or liver for orientation of the array and control for the staining processes (Figure 1B). Non-diseased and PD samples were mounted in separate blocks with the samples sorted by the date of collection. The TMAs were sectioned at $2.5 \mu \mathrm{m}$ thickness. The first slide was stained for HE and the second for $\alpha$-synuclein. These stainings were performed to verify that all specimens in the TMAs were correctly annotated and in order 
to exclude that the non-diseased TMAs included brain tissues with $\alpha$-synucleopathies (Appendix A, Figure A1).

A

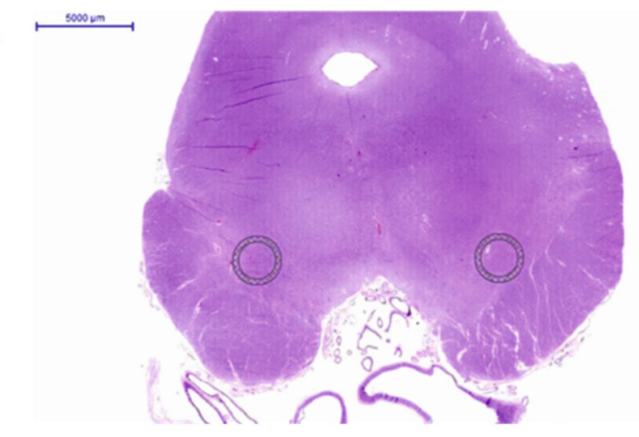

B

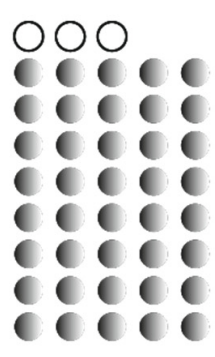

C

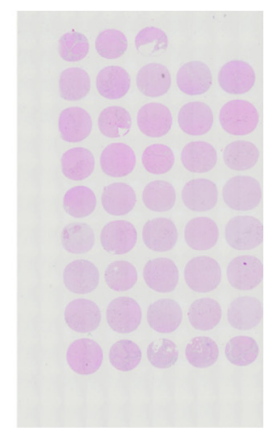

Figure 1. (A). Photomicrograph of a cross-section from a human mesencephalon stained with HE showing the area annotated for the punching of the SNc (circles). (B). Schematic drawing of a TMA with the human SNc samples (gray circles) and the non-neuronal tissue samples (open circles). (C). Representative photomicrograph of a TMA stained with HE.

A total of 56 cases were included for the non-diseased TMA (23 female and 33 male samples) for assessment of the age-dependent Nogo-A expression in dopaminergic neurons and analysis of Nogo-A-ir and tyrosine hydroxylase (TH) positive (TH-ir) cell densities. The mean age of all tissue samples was $67.1 \pm 1.7$ years, with similar ages for the female and male samples $(67.5 \pm 1.7$ and $66.9 \pm 2.0$, respectively). The age of the samples extended from 32 to 91 years (females 32 to 91 years and males 41 to 88 years, respectively; Tables A1 and A2).

For the diseased TMA samples of patients diagnosed with Morbus Parkinson $(n=19)$ were included, as shown in Table A3. The mean age of all tissue samples was $78.4 \pm 1.2$ years with similar ages for the female and male samples (77.3 \pm 2.1 and $78.9 \pm 1.5$, respectively). The age of the samples ranged from 68 to 90 years (Table A3).

\subsection{Immunohistochemistry}

Slides were dewaxed in two baths of fresh Xylol for 20 and $5 \mathrm{~min}$, hydrated through descending ethanol concentrations (100\%, 95\%, 80\%, 70\% and 35\% each for $3 \mathrm{~min}$ ) and transferred to aqua dest. After two washes for $15 \mathrm{~min}$ with $0.1 \mathrm{M}$ phosphate buffered saline (PBS) ( $\mathrm{pH} 7.4$ ), slides were exposed to epitope retrieval with citrate buffer (Appendix B; Figure A2). Thereafter, slides were blocked for 45 min with $10 \%$ horse serum in $0.1 \%$ Triton X-100 and incubated over night at $4{ }^{\circ} \mathrm{C}$ with the primary antibodies (rabbit polyclonal antiNogo-A, Santa Cruz, sc-25660; mouse monoclonal anti-TH antibody, Millipore MAB5280; see also Appendix B) diluted in PBS containing 2.5\% horse serum and $0.1 \%$ Triton X-100. Following washes in PBS $(4 \times 15 \mathrm{~min})$ to remove unbound antibodies the sections were incubated for $2 \mathrm{~h}$ with secondary antibodies (Alexa-Fluor donkey anti-mouse $488 \mathrm{~nm}$ and Alexa-Fluor donkey anti-rabbit $594 \mathrm{~nm}$ or Alexa-Fluor donkey anti-mouse $594 \mathrm{~nm}$ and Alexa-Fluor donkey anti-rabbit $488 \mathrm{~nm}$ for the mouse and rabbit anti-Nogo-A antibodies, respectively; Thermo Fisher Scientific, Carlsbad, CA, USA, 1:250) and a fluorescent dye for detection of the cell nuclei (Hoechst 33352, 1:10000, Thermo Fisher Scientific). Thereafter the sections were washed in PBS $(4 \times 15 \mathrm{~min})$ and mounted in $0.1 \mathrm{M}$ PBS containing $50 \%$ glycerol.

\subsection{Cell Count Analysis}

Only cells with a clear morphology of neurons were counted in a blinded manner. Hence, Nogo-A positive cells that had a small cell body and looked morphologically similar to glia cells were not included. The number of cells were analyzed using an Olympus microscope (BX51) equipped with a motorized stage (MW Tango) that was connected to a digital camera (Olympus DP72) and connected to a PC with a calibrated neuron 
tracing software (Cellsens Dimension; Olympus Schweiz AG, Wallisellen, Switzerland). The following approach was used for the analysis of TH and Nogo-A positive neurons and the rate of co-localization: after acquiring multi-image alignments taken from each TMA, a virtual grid was overlaid and cells counted in the corresponding squares at a magnification of $10 \times$ (Appendix D; Figure A4). The number of TH positive, Nogo-A positive and cells expressing both markers per tissue sample was the sum of all fields analyzed covering this sample. The numbers were then transcribed into an excel spreadsheet Table and the co-localization rate was calculated. The specimens with a very weak or unclear TH-ir staining or complete absence of TH-ir cells were excluded from the TMA analysis. In 8 cases of the control TMA and 5 cases of the PD, only one side per specimen was available on the TMA, thus the counts were based on a single sample; otherwise, the mean value of the right and left SNc samples was taken.

\subsection{Statistical Analysis}

For statistical analysis, a commercially available software package was used (GraphPad Prism 7, La Jolla, CA, USA). Statistical significance of two groups only was assessed by two-tailed unpaired t-test or by the non-parametric Mann-Whitney test, based on the outcome of the D'Agostino and Pearson normality test. Linear regression was applied for correlation analyzes of co-localization rates and age. Statistical significance was set at $p<0.05$. Data are presented as mean \pm SEM.

\section{Results}

\subsection{Nogo-A Is Expressed in DAneurons Human SNc}

We first determined that Nogo-A is expressed in human SNc. Immunohistochemical analysis using the $\mathrm{DAB}$ chromogen revealed a wide distribution and a specific staining in neuronal-like cells (Figure A2). We then verified that DA neurons express Nogo-A by means of a double immunofluorescence immunohistochemistry (Figure 2; Appendix $C$; Figure A3).
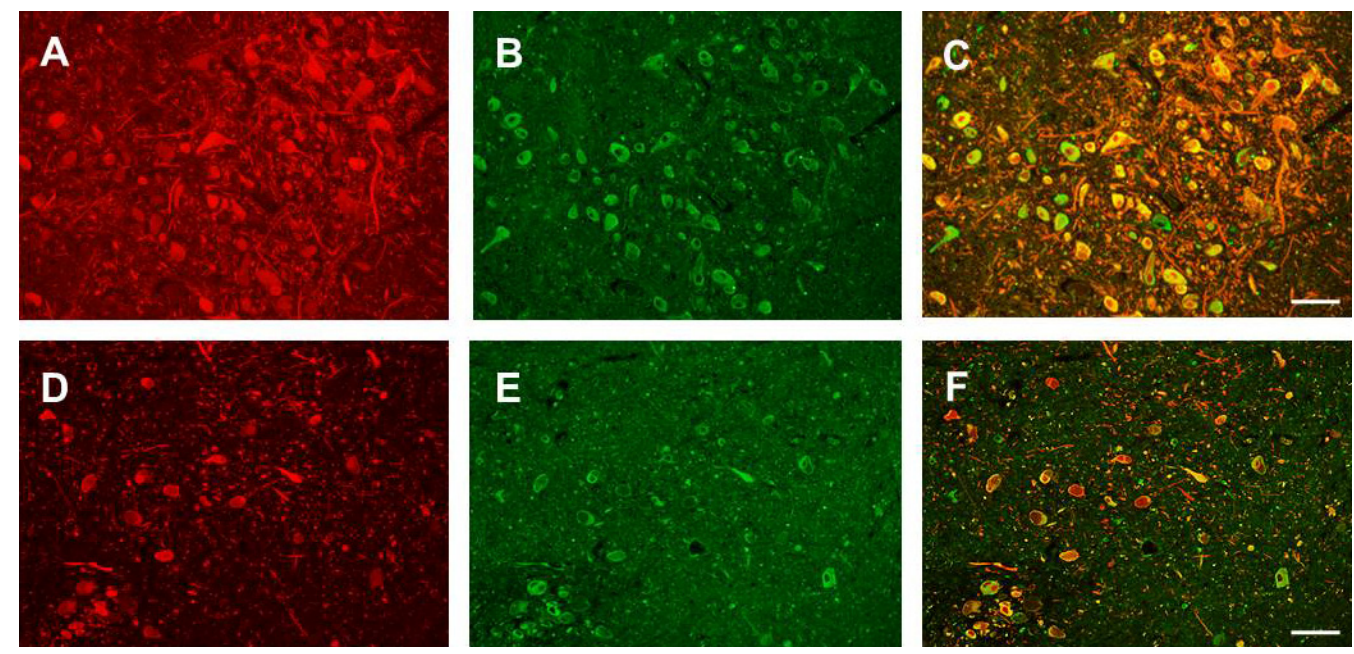

Figure 2. Digitalized photomicrographs of a 72-year-old PD male (upper row) and a 90-year-old PD male (lower row) specimen stained for tyrosine hydroxylase (A,D) and Nogo-A (B,E). Note the overall higher densities of neurons and a higher co-localization rate in the 72-year-old as compared to the 90-year-old specimen (C,F). Scale bars: $100 \mu \mathrm{m}$.

\subsection{Co-Localization Rates Increase with Age in the Non-Diseased Brains}

We detected a mean co-localization rate of $80.6 \pm 2.2 \%$ for all analyzed TH-ir neurons expressing Nogo-A. Importantly, the co-localization rate increased with age and displayed a statistical significant correlation $\left(\mathrm{Y}=0.4344 \times \mathrm{X}+51.44 ; \mathrm{F}(1,54)=6.878 ; \mathrm{r}^{2}=0.1130\right.$, $p<0.05$ ) (Figure 3). 


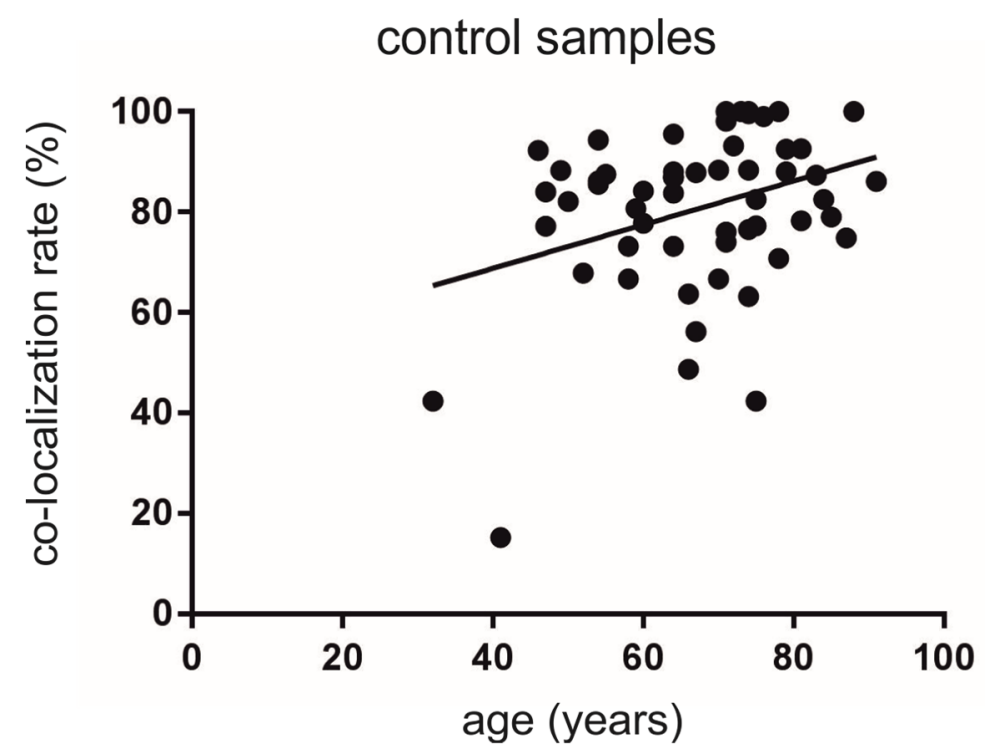

Figure 3. Analysis of the co-localization rates of TH-ir neurons also expressing Nogo-A depending on the age in the human SNc from non-diseased individuals. We found a significantly higher co-localization rate with increasing age $(p<0.05)$.

\subsection{Lower Numbers of TH-ir Neurons in Normal Aging}

The mean number of neurons was $18.5 \pm 1.3$ per $\mathrm{mm}^{2}$ and $25.2 \pm 1.6$ per $\mathrm{mm}^{2}$ for TH-ir and Nogo-A-ir neurons, respectively (Figure A5). When we assessed the number of TH-ir neurons depending on age, we detected a tendency for lower cell densities with increasing age $\left(\mathrm{Y}=-0.1474 \times \mathrm{X}+28.35 ; \mathrm{F}(1,54)=1.980 ; \mathrm{r}^{2}=0.0354, p=0.165\right)$ (Figure 4A). No significant changes were observed for the density of Nogo-A-ir neurons $\left(\mathrm{Y}=0.136 \times \mathrm{X}+16.07 ; \mathrm{F}(1,54)=1.103 ; \mathrm{r}^{2}=0.0200, p=0.298\right)$ (Figure 4B).

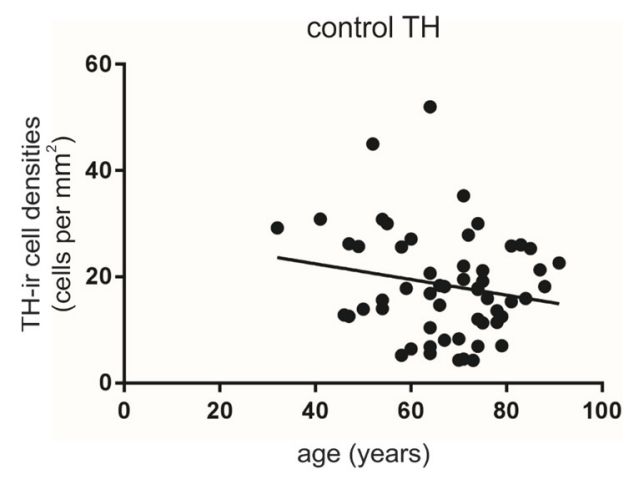

A

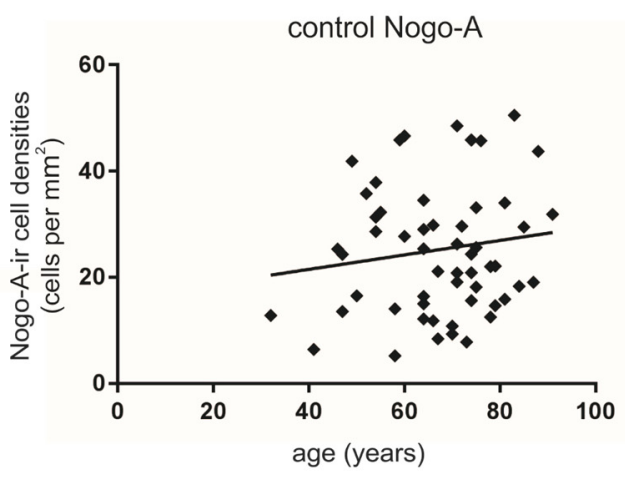

B

Figure 4. Analysis of TH-ir (A) and Nogo-A-ir cell densities (B) per $\mathrm{mm}^{2}$ depending on the age in the human SNc from non-diseased individuals. Both markers did not display a significant association with age.

\subsection{Co-Localization Rates in PD Decrease Depending on Age}

The mean co-localization rate of TH-ir neurons expressing Nogo-A was $62.3 \pm 3.9 \%$ for all PD specimens (Figure A5).

Interestingly, we detected a significant decrease in the co-localization rate with increasing age for all $\mathrm{PD}$ samples included $\left(\mathrm{Y}=-1.562 \times \mathrm{X}+184.8 ; \mathrm{F}\left(1,17=5.067 ; \mathrm{r}^{2}=0.2296\right.\right.$, $p<0.05$ ) (Figure 5). 


\section{PD samples}

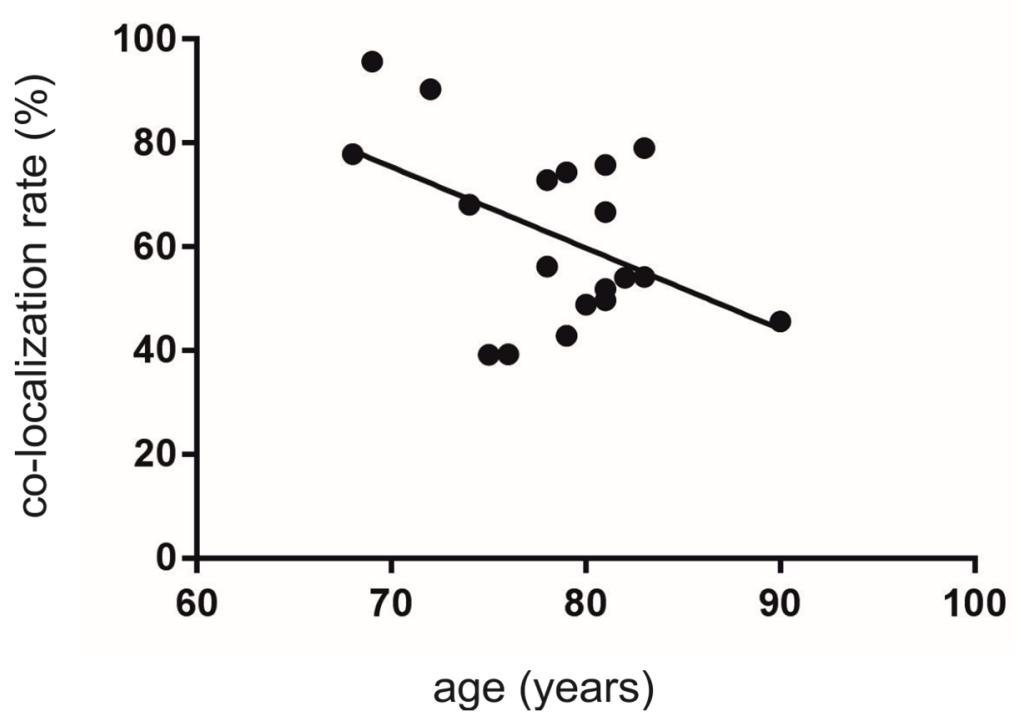

Figure 5. Analysis of the co-localization rates of TH-ir neurons also expressing Nogo-A depending on the age in the human SNc from PD individuals. There was a significant association with increasing age, showing lower levels of co-localization $(p<0.05)$.

\subsection{Age Is Associated with Lower Numbers of TH-ir and Nogo-A-ir Neurons in PD}

The mean number of cells was $20.6 \pm 2.7$ per $\mathrm{mm}^{2}$ and $17.3 \pm 2.7$ per $\mathrm{mm}^{2}$ for TH-ir and Nogo-A-ir neurons, respectively. When we assessed the number of TH-ir and Nogo-Air neurons depending on age, we detected a decrease with increasing age. This decrease showed a tendency for TH-ir neurons $\left(\mathrm{Y}=-0.8993 \times \mathrm{X}+91.52 ; \mathrm{F}(1,17)=3.062 ; \mathrm{r}^{2}=0.1526\right.$, $p=0.1$ ) (Figure 6A) and reached statistical significance for the number of Nogo-A-ir neurons $\left(\mathrm{Y}=-1.205 \times \mathrm{X}+111.8 ; \mathrm{F}(1,17)=6.661 ; \mathrm{r}^{2}=0.2815, p<0.05\right)$ (Figure $6 \mathrm{~B}$ ).

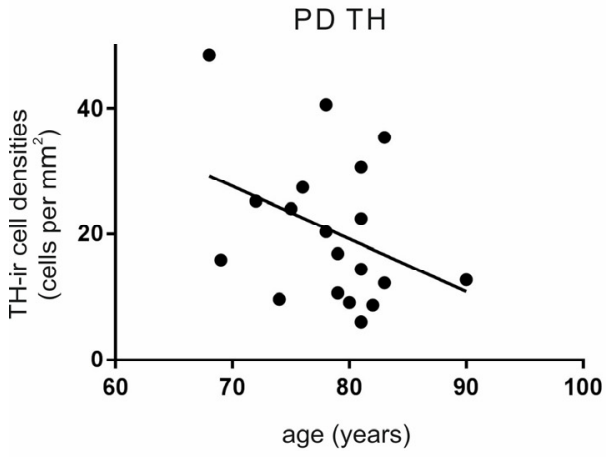

A

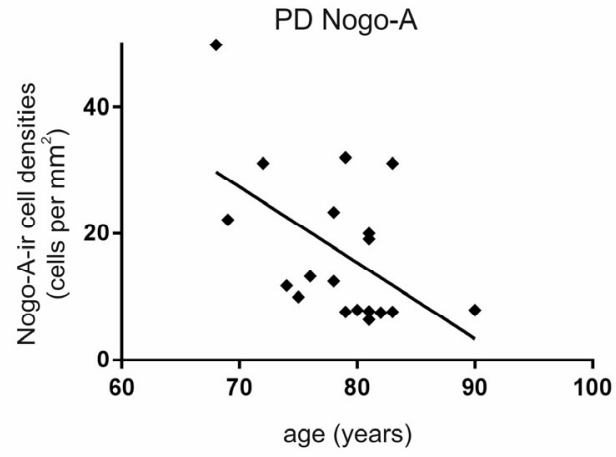

B

Figure 6. Analysis of TH-ir (A) and Nogo-A-ir cell densities (B) per $\mathrm{mm}^{2}$ depending on the age in the human SNc from PD individuals. Both markers displayed a significant decline with age.

\section{Discussion}

Aging is the primary risk factor of PD. Aging and PD share common features with aging, being considered a pre-parkinsonian state. In fact, although a general decline of nigro-striatal system functionality occurs during normal aging, this alone is not sufficient to cause PD. Rather, aging is associated with alterations at a cellular level that predispose the loss of DA neurons in the SNc, which is considered the cardinal event in the pathogenesis of PD [28]. Aging results in global changes in plasticity in the central nervous system, but SNc seems to be moderately affected compared to other brain regions [29]. Nogo-signaling plays a key role in the context of plasticity perturbations, and there is evidence that the 
expression of this complex signaling system is timely and regionally regulated in aging mice brains [30].

To the best of our knowledge, this is the first description of Nogo-A expression in human SNc in postmortem tissues from PD and non-diseased specimens. So far, Nogo-A in DA neurons has been reported in animals and in a human midbrain cell line [19,31]. Similar to previous observations in rodents, we report a fairly abundant Nogo-A co-localization with TH [18]. The principal finding of the present work consists of the substantial divergence of the TH/Nogo-A pattern of co-expression in relation with aging in PD compared to non-diseased specimens. In fact, TH-ir/Nogo-A-ir densities declined significantly with increasing age in the PD samples but not in the non-diseased. These differences are consistent with the concept of heterogeneity of DA neuron vulnerability [11] and seem to rely mostly on the Nogo-A-ir densities in the two groups. The TH-ir densities declining with age in the $\mathrm{SNc}$ are consistent with a progressive deterioration of the nigrostriatal system functionality during aging. Therefore, these results seem to support the hypothesis that consider PD as an exacerbation of the degenerative effects on the nigral DA neurons that accumulate during lifetime [32,33]. On the other hand, the opposite trends of TH/Nogo-A co-expression during aging in the two experimental groups examined suggest that distinct phenotypic changes in the SNc landmark the pathogenesis of PD. Accordingly, past investigations on the ultrastructural abnormalities in dying DA neurons have disclosed that the apoptotic processes differ between successful aging and Parkinson's disease $[8,28]$. The ascending slope of Nogo-A expression with age in the non-diseased SNc samples is another striking observation of our study. These results challenge the current knowledge on Nogo-A expression in the aging brain. In fact, it has been reported that in mouse brains, the expression of Nogo-A protein declines during aging [34]. Others have associated the reduced levels of Nogo-A mRNA in the cortex and hippocampus of aging rats with a decline in synaptic plasticity [35]. Based on the quantitative gene expression level analysis in different brain areas (but not including the mesencephalon), Smedfords and colleagues concluded that in adulthood and aging the Nogo signaling system is extremely stable [30]. We have previously found that one month after intrastriatal lesion with 6-OHDA, rats show a substantial loss of Nogo-A expressing cells in the SNc that parallel the reduction in TH-ir neurons [18]. However, we have also reported that TH-ir neurons' vulnerability to 6-OHDA differs according to the co-expression of Nogo-A, with the Nogo-A-ir neurons better withstanding the toxic insult [18]. The results of the present study hence represent a shift in the paradigm of Nogo-A/TH co-localization in respect to our earlier findings. These results raise fundamental questions; namely, whether the Nogo-A expression identifies a population of nigral neurons with different vulnerability and functions or the alterations in Nogo-A expression pattern are the cause/effect of the changes occurring in normal aging and PD samples. It is intriguing to speculate that an increase in Nogo-A expression in DA neurons underlies compensatory adaptations to cope with mild or acute degenerative conditions, such as those occurring in aging in humans or those exerted by 6-OHDA in rats, respectively. There is growing evidence that Nogo participates in different processes related to apoptosis and autophagy [36,37]. However, whether Nogo-A plays a direct role in regulating the dopaminergic neurons viability in healthy and diseased brains is currently not known. These features of Nogo-A offer perspectives for novel interventions to contrast cognitive decline in aging and pathogenic neurodegeneration. Indeed, suppression of Nogo-A signaling supports functional regeneration by promoting neuronal plasticity and axonal sprouting. Moreover, a number of preclinical and clinical studies have demonstrated that Nogo-A inhibition has a therapeutic potential for neurodegenerative conditions, such as PD [16], MS [38], spinal cord injury [39] and stroke [40].

The TMA methodology employed in the present work is a powerful tool for exploring new biomarkers and drug targets for neurodegenerative diseases such as PD. Few general and specific caveats of this technology should also be acknowledged. These limitations are inherent to the TMA technique [41]. With regards to the present work, it was not possible to retrieve information about underlying diseases in the samples as well as the agonal 
state and postmortem interval. Moreover, despite the efforts for an accurate sampling methodology, small variations in the sampling region cannot be excluded. In fact, besides the individual neuroanatomical differences, it should be considered that the core size on the array is considerably small when compared to the entire SNc from which it has been isolated. Furthermore, the analyses (counting) were not automated. However, even considering these limitations, the TH/Nogo-A co-localization displays a clear association with age in the non-diseased as in the PD cohort. In the context of variability, we have observed different co-localization and cell density rates among the right and left $\mathrm{SNc}$ samples of the same specimen. These differences might be the result of the sampling methodology, but might also undermine the nature of the physiology of neurodegeneration, which has typically a unilateral onset in PD [3]. Clearly, the lack of clinical information of the sample donors, including the stage of the disease, time of disease onset and types of symptoms (including motor and no-motor symptoms) limit the possibility to infer detailed conclusions regarding the differences of $\mathrm{TH} / \mathrm{Nogo}-\mathrm{A}$ co-localization in $\mathrm{SNc}$ in the context of PD neurodegeneration.

Together with age, sex is an important risk factor of PD, with women being less prone to develop the disease $[42,43]$ and with a delayed onset of the motor symptoms compared to men [44]. Moreover, non-motor symptoms are more severe and frequent in women [45], while the cognitive decline progresses more rapidly in male PD patients [46]. The reasons underlying this difference are not completely understood but multiple observations suggest that estrogen has neuroprotective effect on the nigrostriatal dopaminergic system [47]. Unfortunately, due to the small number of samples, the present study does not allow us to define whether differences in TH/Nogo-A co-expression might contribute to sex differences in dopaminergic neuron vulnerability, as recently described for other markers such as VGLUT [48].

The present study highlights this perspective by dissecting the biology of Nogo-A. Understanding the function of Nogo-A in DA neurons might shed light on the pathogenesis of PD and eventually open new scenarios for its diagnosis and therapy. For this purpose, further analyses in larger groups of samples are needed. In particular, the relation with the several factors involved in the onset and progression of the disease, including the differences in aging females and males, the effect of the severity of the symptoms and the association with other markers of neurodegeneration as $\alpha$-synuclein need to be addressed in more detail.

\section{Conclusions}

The relevance of the changes in the TH/Nogo-A expression pattern reported here remains to be investigated, but to the best of our knowledge, this study is the first to characterize the alterations in these markers' co-expression in human postmortem tissue samples. These results might advance our understanding of the vulnerability of DA neurons. The examination of TH/Nogo-A co-localization might thus provide a novel perspective to understand the spectrum of alterations occurring in PD and develop novel therapeutic approaches.

Author Contributions: Conceptualization, S.D.S., E.H., L.A. and H.R.W.; methodology, G.-C.E. and S.S.; formal analysis, G.-C.E., S.D.S. and H.R.W.; investigation, G.-C.E. and S.S.; data curation, G.-C.E. and L.A.; writing-original draft preparation, G.-C.E., S.D.S. and H.R.W.; writing-review and editing, S.D.S. and H.R.W.; project administration, H.R.W.; funding acquisition, H.R.W. All authors have read and agreed to the published version of the manuscript.

Funding: This research was funded by the Swiss Parkinson Foundation, the HANELA Foundation, Switzerland and the Research Grant of the Inselspital, University Hospital Bern, Switzerland (RGI84800855). 
Institutional Review Board Statement: The study was conducted according to the guidelines of the Declaration of Helsinki. Ethical review and approval were waived for this study, due to the fact that a general ethical permission from the authorities was available at the Institute of Pathology, University Bern for the use of human specimen for research purposes.

Informed Consent Statement: Patient consent was waived due to fact that a general ethical permission from the authorities was available at the Institute of Pathology, University Bern for the use of human specimen for research purposes.

Data Availability Statement: Data are contained within the article.

Acknowledgments: The expert technical assistance form Susanne Wälchli is gratefully acknowledged. We thank the team of the TRU of the Institute of Pathology, University Bern for their support. We thank Bettina Rotzetter for careful reading and editing the manuscript.

Conflicts of Interest: The authors declare no conflict of interest. Moreover, the funders had no role in the design of the study; in the collection, analyses, or interpretation of data; in the writing of the manuscript, or in the decision to publish the results.

\section{Appendix A. Immunohistochemistry for $\alpha$-Synuclein}

The stainings for $\alpha$-synuclein were performed by the Institute of Pathology, University of Bern. The TMA slides were dried and baked at $60{ }^{\circ} \mathrm{C}$ for $30 \mathrm{~min}$ prior to use. Immunostaining was performed by automated staining using Bond RX (Leica Biosystems) immunostainer using the following protocol: Slides were dewaxed in Bond dewax solution (product code AR9222, Leica Biosystems). Heat-induced epitope retrieval (EDTA based $\mathrm{pH}$ 9.0; code AR9640, Leica Biosystems) was performed for $30 \mathrm{~min}$ at $95^{\circ}$. Mouse anti $\alpha$-synuclein antibodies (Novocastra NCL-L-ASYN) were diluted 1:200 and incubated for $30 \mathrm{~min}$. Samples were incubated with horseradish peroxidase-polymer for $15 \mathrm{~min}$ and subsequently visualized using 3,3-diaminobenzidine (DAB) as brown chromogen (Bond polymer refine detection, Leica Biosystems, Ref DS9800) for $10 \mathrm{~min}$ (Figure A1).
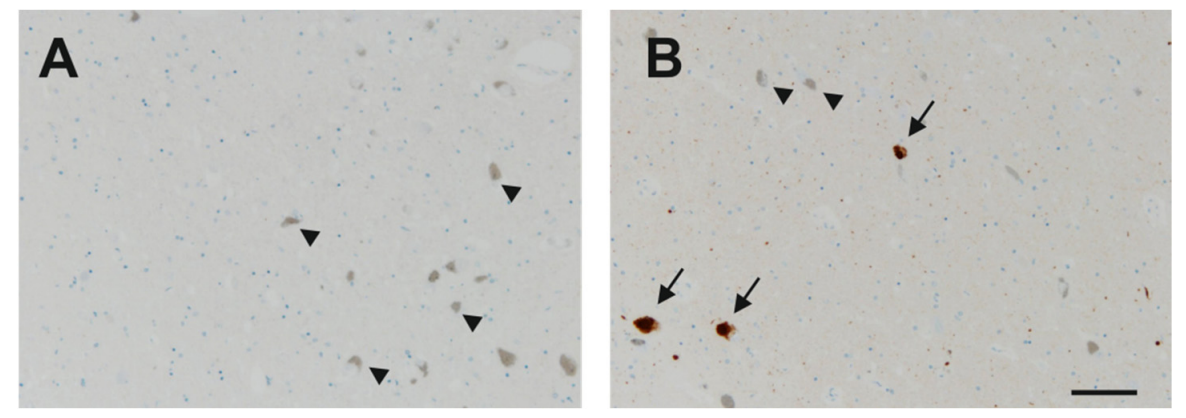

Figure A1. Microphotographs of the human SNc from a non-diseased sample (A) and from a PD specimen with $\alpha$-synuclein (arrows) (B) inclusions. Note the pigmented DA neurons free of $\alpha$ synuclein (arrowheads). Scale bar: $100 \mu \mathrm{m}$.

Table A1. Female specimens included in the non-diseased TMA.

\begin{tabular}{cc}
\hline Sample Number & Age \\
\hline 1 & 32 \\
2 & 46 \\
3 & 50 \\
4 & 52 \\
5 & 55 \\
6 & 58 \\
7 & 59 \\
8 & 64 \\
9 & 64 \\
10 & 64
\end{tabular}


Table A1. Cont.

\begin{tabular}{cc}
\hline Sample Number & Age \\
\hline 11 & 67 \\
12 & 70 \\
13 & 73 \\
14 & 74 \\
15 & 74 \\
16 & 74 \\
17 & 75 \\
18 & 79 \\
19 & 79 \\
20 & 83 \\
21 & 84 \\
22 & 85 \\
23 & 91 \\
\hline
\end{tabular}

Table A2. Male specimens included in the non-diseased TMA.

\begin{tabular}{|c|c|}
\hline Sample Number & Age \\
\hline 1 & 41 \\
\hline 2 & 47 \\
\hline 3 & 47 \\
\hline 4 & 49 \\
\hline 5 & 54 \\
\hline 6 & 54 \\
\hline 7 & 54 \\
\hline 8 & 58 \\
\hline 9 & 60 \\
\hline 10 & 60 \\
\hline 11 & 64 \\
\hline 12 & 64 \\
\hline 13 & 64 \\
\hline 14 & 66 \\
\hline 15 & 66 \\
\hline 16 & 67 \\
\hline 17 & 70 \\
\hline 18 & 71 \\
\hline 19 & 71 \\
\hline 20 & 71 \\
\hline 21 & 71 \\
\hline 22 & 72 \\
\hline 23 & 74 \\
\hline 24 & 74 \\
\hline 25 & 75 \\
\hline 26 & 75 \\
\hline 27 & 76 \\
\hline 28 & 78 \\
\hline 29 & 78 \\
\hline 30 & 81 \\
\hline 31 & 81 \\
\hline 32 & 87 \\
\hline 33 & 88 \\
\hline
\end{tabular}


Table A3. Specimens included in the PD TMA.

\begin{tabular}{ccc}
\hline Sample Number & Gender & Age \\
\hline 1 & Female & 69 \\
2 & Female & 75 \\
3 & Female & 76 \\
4 & Female & 80 \\
5 & Female & 81 \\
6 & Female & 83 \\
7 & Male & 68 \\
8 & Male & 72 \\
9 & Male & 74 \\
10 & Male & 78 \\
11 & Male & 78 \\
12 & Male & 79 \\
13 & Male & 79 \\
14 & Male & 81 \\
15 & Male & 81 \\
16 & Male & 81 \\
17 & Male & 82 \\
18 & Male & 83 \\
19 & Male & 90 \\
\hline
\end{tabular}

\section{Appendix B. Immunohistochemistry for Establishment of Best Staining Method}

Slides were first dewaxed in fresh Xylol for $20 \mathrm{~min}$ and another $5 \mathrm{~min}$, hydrated through descending ethanol concentrations (100\%, 95\%, 80\%, 70\%, 35\% each for $3 \mathrm{~min}$ ) and transferred to aqua dest. After two washes for $15 \mathrm{~min}$ with $0.1 \mathrm{M}$ phosphate buffered saline (PBS) (pH 7.4) slides were exposed to epitope retrieval. This was carried out by boiling the sections in citrate buffer ( $10 \mathrm{mM}$ Citric acid, $0.05 \%$ Tween $20, \mathrm{pH} 6.0$ ) for $30 \mathrm{~min}$. Slides were cooled down for $20 \mathrm{~min}$ and washed in $0.1 \mathrm{M}$ PBS for $10 \mathrm{~min}$ prior to the immunhistochemical stainings (vide infra). Unmasking antigens after fixation resulted in an enhanced the staining intensity for TH (Figure A2).
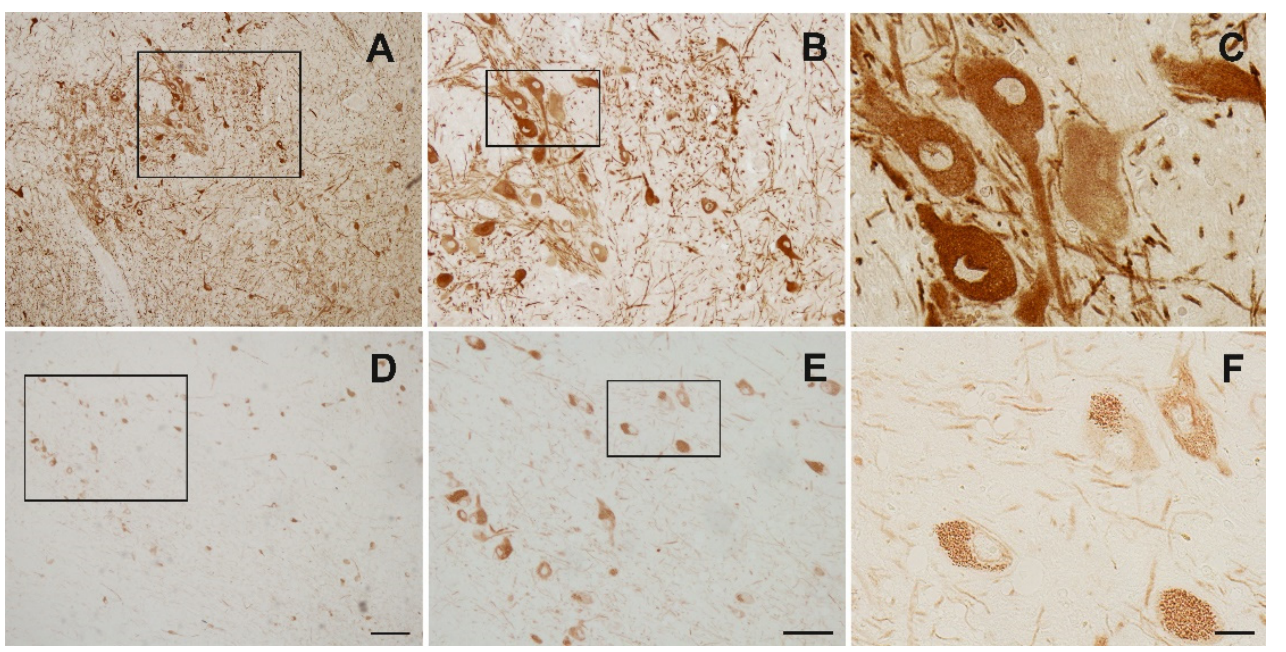

Figure A2. Representative digitalized photomicrographs of the human SNc stained for TH. Note the improved staining quality in the antigen retrieval treated sections $(\mathbf{A}-\mathbf{C})$ compared to not treated (D-F). (B,E) are magnifications from the box in $(\mathbf{A}, \mathbf{D}),(\mathbf{C}, \mathbf{F})$ are magnifications from $(\mathbf{B}, \mathbf{E})$. Scale bars: $200 \mu \mathrm{m}(\mathbf{A}, \mathbf{D}), 100 \mu \mathrm{m}(\mathbf{B}, \mathbf{E}), 20 \mu \mathrm{m}(\mathbf{C}, \mathbf{F})$.

Thereafter, slides were blocked for 45 min with $10 \%$ horse serum in $0.1 \%$ Triton X-100 and incubated over night at $4{ }^{\circ} \mathrm{C}$ with the primary antibodies diluted in PBS containing $2.5 \%$ horse serum and $0.1 \%$ Triton X-100. Following washes in PBS $(4 \times 15 \mathrm{~min})$ to remove 
unbound antibodies, the sections were incubated for $2 \mathrm{~h}$ with biotinylated secondary antibodies (Vector Laboratories) diluted 1:200 in PBS containing 0.1\% Triton X-100 and $2.5 \%$ horse serum. The endogenous peroxidase activity was blocked with a solution of $10 \%$ $\mathrm{H}_{2} \mathrm{O}_{2}$ and $10 \%$ methanol in $0.1 \mathrm{M}$ PBS for $10 \mathrm{~min}$. Thereafter, the sections were washed in PBS ( $415 \mathrm{~min})$ and subsequently incubated for $60 \mathrm{~min}$ at room temperature with an avidin-biotin-peroxidase complex (VECTASTAIN ${ }^{\circledR}$ ABC-Peroxidase Kit; 1:250, PK-4000; Vector Laboratories, Servion, Switzerland) in combination with the 3,3-diaminobenzidine (DAB) Substrate Kit (34002, ThermoFischer Scientific). Finally, the sections were dehydrated in a series of alcohol dilutions (70\%, 95\%, 100\%, alcohol), cleared in Xylene and mounted in Eukitt.

In order to find the best staining protocol for detection of Nogo-A and $\mathrm{TH}$ in the TMAs, we used sections of a 45-year-old non-parkinsonian male specimen. Both the rabbit polyclonal anti-Nogo-A antibody (Santa Cruz, sc-25660) in combination with the mouse monoclonal anti-TH antibody (Millipore, MAB5280) were used at different dilutions. The polyclonal Nogo-A antibody has been used successfully by our and other labs performing immunohistochemical analyses in rat, mouse and monkey tissues [18,19,49-52]. Similarly, the anti-TH antibody has been shown to be a specific marker for $\mathrm{TH}$ in our lab for many years $[16,18,53,54]$.

Based on the outcomes of our extensive test stainings, we performed the quantifications of the TMA's using the anti-Nogo-A and the anti-TH antibody at a dilution of 1:250 and 1:1000, respectively and antigen retrieval.

\section{Appendix C. A Subpopulation of Neurons in the SNc Express Nogo-A Only}

Subpopulations of neurons only expressed one marker, i.e., TH or Nogo-A (Figure A3). Overall, about $20 \%$ of the Nogo-A positive neurons did not co-localize with TH while $80 \%$ did. Hence, more Nogo-A neurons presented with co-localization.
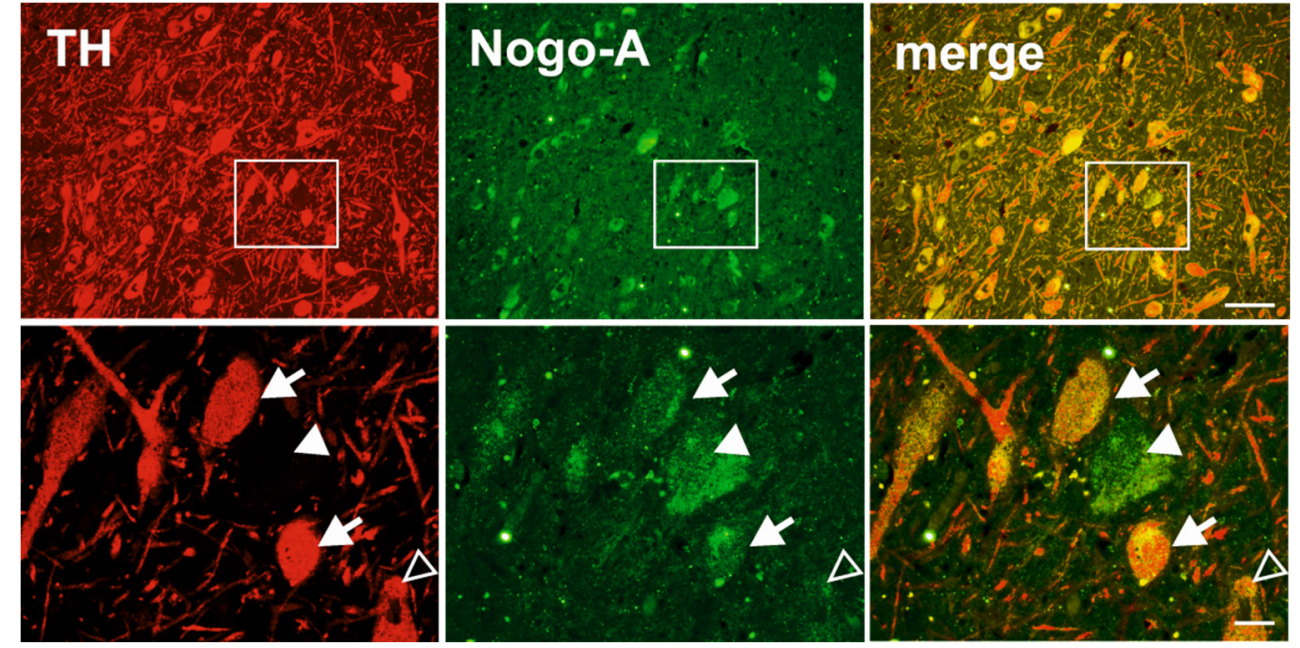

Figure A3. Representative digitalized photomicrographs of the human SNc stained for TH and NogoA. Lower panels show magnifications of boxed areas in the upper panels. Note some cells showed immunoreactivity for Nogo-A (arrowhead) or TH only (open arrowhead) while other neurons express both markers (arrows). Scale bars: $100 \mu \mathrm{m}$ (top row), $20 \mu \mathrm{m}$ (bottom row).

\section{Appendix D. Cell Count Approach}

On the acquired multi-images taken from each TMA, a virtual grid was overlaid and cells counted in the corresponding squares at a magnification of $10 \times$ (Figure A4). The area under the $10 \times$ magnification was $577,284 \mu \mathrm{m}^{2}$. Hence, cell numbers counted in all fields of a specimen were multiplied by a factor of 1.732, so we could extrapolate for the TH-positive and Nogo-A positive cell densities per $\mathrm{mm}^{2}$. The number of cells was the sum 
of all fields analyzed covering this sample. A summary of the gathered data is given in Figure A5.
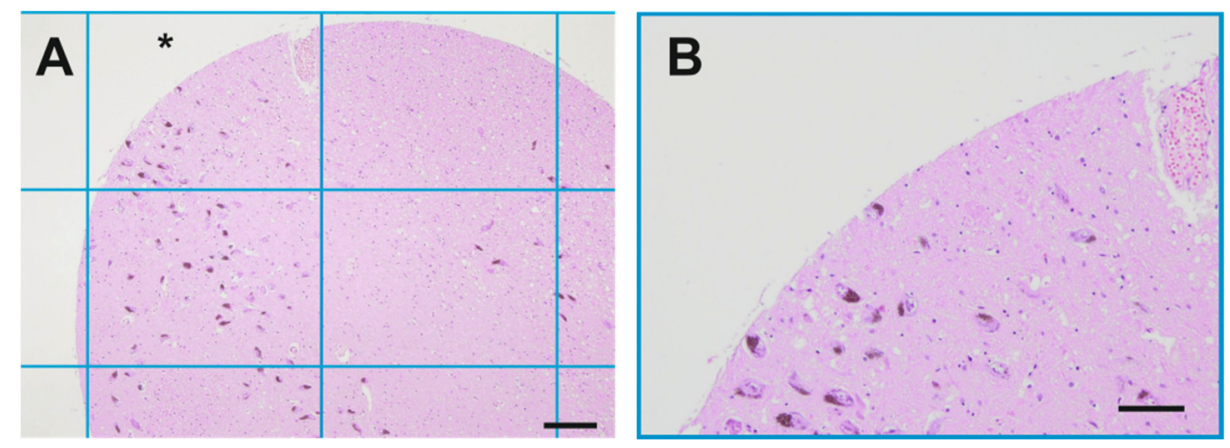

Figure A4. The photomicrograph shows a section of a HE stained MIA (A) taken at a magnification of $4 \times$ with an overlaid grid representative for the counting method. In each square (star) TH positive, Nogo-A positive cells and neurons expressing both markers were counted (magnification 10×; (B)). Scale bars: $200 \mu \mathrm{m}(\mathbf{A}), 100 \mu \mathrm{m}(\mathbf{B})$.
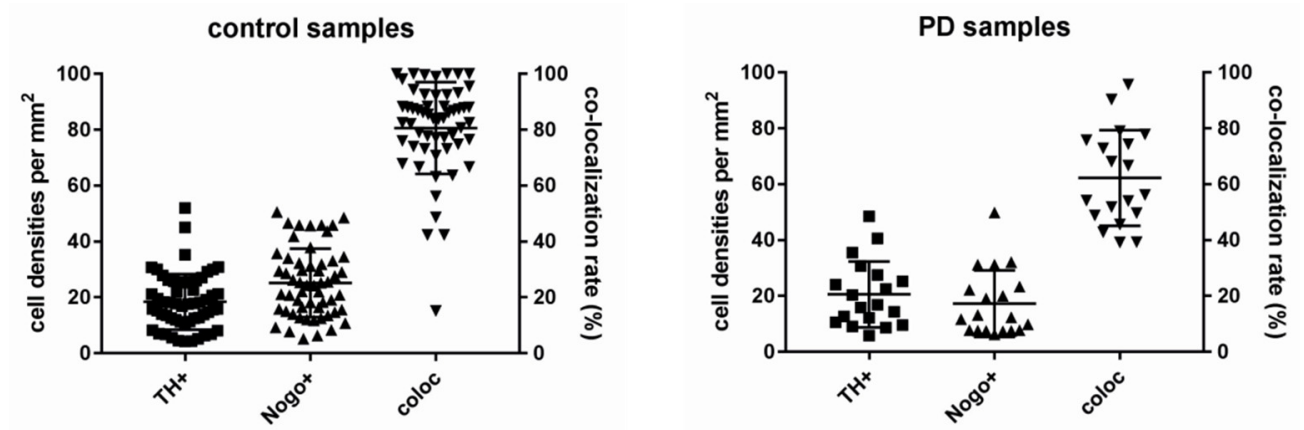

Figure A5. Summary of TH-ir, Nogo-A-ir cell densities per $\mathrm{mm}^{2}$ and rate of co-localization in control and PD samples. Values are given as mean \pm SD.

\section{References}

1. GBD 2016 Parkinson's Disease Collaborators. Global, regional, and national burden of Parkinson's disease, 1990-2016: A systematic analysis for the Global Burden of Disease Study 2016. Lancet Neurol. 2018, 17, 939-953. [CrossRef]

2. Bogetofte, H.; Alamyar, A.; Blaabjerg, M.; Meyer, M. Levodopa Therapy for Parkinson's Disease: History, Current Status and Perspectives. CNS Neurol. Disord. Drug Targets 2020, 19, 572-583. [CrossRef]

3. Lees, A.J.; Hardy, J.; Revesz, T. Parkinson's disease. Lancet 2009, 373, 2055-2066. [CrossRef]

4. Surmeier, D.J.; Obeso, J.A.; Halliday, G.M. Selective neuronal vulnerability in Parkinson disease. Nat. Rev. Neurosci. 2017, 18, 101-113. [CrossRef]

5. Mouatt-Prigent, A.; Agid, Y.; Hirsch, E.C. Does the calcium binding protein calretinin protect dopaminergic neurons against degeneration in Parkinson's disease? Brain Res. 1994, 668, 62-70. [CrossRef]

6. Rodríguez, M.; Barroso-Chinea, P.; Abdala, P.; Obeso, J.; González-Hernández, T. Dopamine cell degeneration induced by intraventricular administration of 6-hydroxydopamine in the rat: Similarities with cell loss in parkinson's disease. Exp. Neurol. 2001, 169, 163-181. [CrossRef]

7. González-Hernández, T.; Barroso-Chinea, P.; Rodríguez, M. Response of the GABAergic and dopaminergic mesostriatal projections to the lesion of the contralateral dopaminergic mesostriatal pathway in the rat. Mov. Disord. 2004, 19, 1029-1042. [CrossRef] [PubMed]

8. Anglade, P.; Vyas, S.; Hirsch, E.C.; Agid, Y. Apoptosis in dopaminergic neurons of the human substantia nigra during normal aging. Histol. Histopathol. 1997, 12, 603-610.

9. Hawkes, C.H. The prodromal phase of sporadic Parkinson's disease: Does it exist and if so how long is it? Mov. Disord. 2008, 23, 1799-1807. [CrossRef]

10. Reeve, A.; Simcox, E.; Turnbull, D. Ageing and Parkinson's disease: Why is advancing age the biggest risk factor? Ageing Res. Rev. 2014, 14, 19-30. [CrossRef] 
11. Damier, P.; Hirsch, E.C.; Agid, Y.; Graybiel, A.M. The substantia nigra of the human brain. II. Patterns of loss of dopaminecontaining neurons in Parkinson's disease. Brain. 1999, 122, 1437-1448. [CrossRef]

12. Schwab, M.E. Nogo and axon regeneration. Curr. Opin. Neurobiol. 2004, 14, 118-124. [CrossRef]

13. Wälchli, T.; Pernet, V.; Weinmann, O.; Shiu, J.Y.; Guzik-Kornacka, A.; Decrey, G.; Yüksel, D.; Schneider, H.; Vogel, J.; Ingber, D.E.; et al. Nogo-A is a negative regulator of CNS angiogenesis. Proc. Natl. Acad. Sci. USA 2013, 110, E1943-E1952. [CrossRef]

14. Schwab, M.E. Functions of Nogo proteins and their receptors in the nervous system. Nat. Rev. Neurosci. 2010, 11, 799-811. [CrossRef]

15. Willi, R.; Aloy, E.M.; Yee, B.K.; Feldon, J.; Schwab, M.E. Behavioral characterization of mice lacking the neurite outgrowth inhibitor Nogo-A. Genes Brain Behav. 2009, 8, 181-192. [CrossRef] [PubMed]

16. Seiler, S.; Di Santo, S.; Widmer, H.R. Nogo-A Neutralization Improves Graft Function in a Rat Model of Parkinson's Disease. Front. Cell. Neurosci. 2016, 10, 87. [CrossRef] [PubMed]

17. Seiler, S.; Pollini, D.; Di Santo, S.; Widmer, H.R. Antagonizing Nogo-receptor 1 promotes the number of cultured dopaminergic neurons and elongates their neurites. Neuroreport 2013, 24, 1047-1052. [CrossRef] [PubMed]

18. Schawkat, K.; Di Santo, S.; Seiler, S.; Ducray, A.D.; Widmer, H.R. Loss of Nogo-A-expressing neurons in a rat model of Parkinson's disease. Neuroscience. 2015, 288, 59-72. [CrossRef]

19. Kurowska, Z.; Brundin, P.; Schwab, M.E.; Li, J.Y. Intracellular Nogo-A facilitates initiation of neurite formation in mouse midbrain neurons in vitro. Neuroscience 2014, 256, 456-466. [CrossRef]

20. Schnell, L.; Schwab, M.E. Axonal regeneration in the rat spinal cord produced by an antibody against myelin-associated neurite growth inhibitors. Nature 1990, 343, 269-272. [CrossRef]

21. Dupuis, L.; Gonzalez de Aguilar, J.L.; di Scala, F.; Rene, F.; de Tapia, M.; Pradat, P.F.; Lacomblez, L.; Seihlan, D.; Prinjha, R.; Walsh, F.S.; et al. Nogo provides a molecular marker for diagnosis of amyotrophic lateral sclerosis. Neurobiol. Dis. 2002, 10, 358-365. [CrossRef] [PubMed]

22. Gil, V.; Nicolas, O.; Mingorance, A.; Ureña, J.M.; Tang, B.L.; Hirata, T.; Sáez-Valero, J.; Ferrer, I.; Soriano, E.; del Río, J.A. Nogo-A expression in the human hippocampus in normal aging and in Alzheimer disease. J. Neuropathol. Exp. Neurol. 2006, 65, 433-444. [CrossRef] [PubMed]

23. Lee, J.-K.; Kim, J.-E.; Sivula, M.; Strittmatter, S.M. Nogo receptor antagonism promotes stroke recovery by enhancing axonal plasticity. J. Neurosci. 2004, 24, 6209-6217. [CrossRef] [PubMed]

24. Willi, R.; Schwab, M.E. Nogo and Nogo receptor: Relevance to schizophrenia? Neurobiol. Dis. 2013, 54, 150-157. [CrossRef]

25. Mohammed, R.; Opara, K.; Lall, R.; Ojha, U.; Xiang, J. Evaluating the effectiveness of anti-Nogo treatment in spinal cord injuries. Neural. Dev. 2020, 15, 1. [CrossRef] [PubMed]

26. Zlobec, I.; Suter, G.; Perren, A.; Lugli, A. A next-generation tissue microarray (ngTMA) protocol for biomarker studies. J. Vis. Exp. 2014, 51893. [CrossRef]

27. Zlobec, I.; Koelzer, V.H.; Dawson, H.; Perren, A.; Lugli, A. Next-generation tissue microarray (ngTMA) increases the quality of biomarker studies: An example using CD3, CD8, and CD45RO in the tumor microenvironment of six different solid tumor types. J. Transl Med. 2013, 11, 104. [CrossRef]

28. Eriksen, N.; Stark, A.K.; Pakkenberg, B. Age and Parkinson's disease-related neuronal death in the substantia nigra pars compacta. J. Neural. Transm. Suppl. 2009, 203-213. [CrossRef]

29. Naskar, A.; Mahadevan, A.; Philip, M.; Alladi, P.A. Aging mildly affects dendritic arborisation and synaptic protein expression in human substantia nigra pars compacta. J. Chem. Neuroanat. 2019, 97, 57-65. [CrossRef]

30. Smedfors, G.; Olson, L.; Karlsson, T.E. A Nogo-Like Signaling Perspective from Birth to Adulthood and in Old Age: Brain Expression Patterns of Ligands, Receptors and Modulators. Front. Mol. Neurosci. 2018, 11. [CrossRef]

31. Buss, A.; Sellhaus, B.; Wolmsley, A.; Noth, J.; Schwab, M.E.; Brook, G.A. Expression pattern of NOGO-A protein in the human nervous system. Acta Neuropathol. 2005, 110, 113-119. [CrossRef] [PubMed]

32. Carvey, P.M.; Punati, A.; Newman, M.B. Progressive dopamine neuron loss in Parkinson's disease: The multiple hit hypothesis. Cell. Transplant. 2006, 15, 239-250. [CrossRef] [PubMed]

33. Chan, C.S.; Gertler, T.S.; Surmeier, D.J. A molecular basis for the increased vulnerability of substantia nigra dopamine neurons in aging and Parkinson's disease. Mov. Disord. 2010, 25, S63-S70. [CrossRef]

34. Kumari, A.; Thakur, M.K. Age-Dependent Decline of Nogo-A Protein in the Mouse Cerebrum. Cell. Mol. Neurobiol. 2014, 34, 1131-1141. [CrossRef] [PubMed]

35. Trifunovski, A.; Josephson, A.; Bickford, P.C.; Olson, L.; Brené, S. Selective decline of Nogo mRNA in the aging brain. Neuroreport 2006, 17, 913-916. [CrossRef] [PubMed]

36. Seiler, S.; Di Santo, S.; Widmer, H.R. Non-canonical actions of Nogo-A and its receptors. Biochem. Pharm. 2016, 100, 28-39. [CrossRef] [PubMed]

37. Pradhan, L.K.; Das, S.K. The Regulatory Role of Reticulons in Neurodegeneration: Insights Underpinning Therapeutic Potential for Neurodegenerative Diseases. Cell. Mol. Neurobiol. 2021, 41, 1157-1174. [CrossRef]

38. Ineichen, B.V.; Kapitza, S.; Bleul, C.; Good, N.; Plattner, P.S.; Seyedsadr, M.S.; Kaiser, J.; Schneider, M.P.; Zörner, B.; Martin, R.; et al. Nogo-A antibodies enhance axonal repair and remyelination in neuro-inflammatory and demyelinating pathology. Acta. Neuropathol. 2017, 134, 423-440. [CrossRef] 
39. Kucher, K.; Johns, D.; Maier, D.; Abel, R.; Badke, A.; Baron, H.; Thietje, R.; Casha, S.; Meindl, R.; Gomez-Mancilla, B.; et al. Firstin-Man Intrathecal Application of Neurite Growth-Promoting Anti-Nogo-A Antibodies in Acute Spinal Cord Injury. Neurorehabil. Neural. Repair 2018, 32, 578-589. [CrossRef]

40. Xu, W.; Xiao, P.; Fan, S.; Chen, Y.; Huang, W.; Chen, X.; Liu, G.; Dang, C.; Zeng, J.; Xing, S. Blockade of Nogo-A/Nogo-66 receptor $1(\mathrm{NgR} 1)$ Inhibits Autophagic Activation and Prevents Secondary Neuronal Damage in the Thalamus after Focal Cerebral Infarction in Hypertensive Rats. Neuroscience 2020, 431, 103-114. [CrossRef]

41. Singh-Bains, M.K.; Mehrabi, N.F.; Tan, A.Y.S.; Faull, R.L.M.; Dragunow, M. Preparation, construction and high-throughput automated analysis of human brain tissue microarrays for neurodegenerative disease drug development. Nat. Protoc. 2021, 16, 2308-2343. [CrossRef]

42. Twelves, D.; Perkins, K.S.; Counsell, C. Systematic review of incidence studies of Parkinson's disease. Mov. Disord. 2003, 18, 19-31. [CrossRef]

43. Tysnes, O.-B.; Storstein, A. Epidemiology of Parkinson's disease. J. Neural. Transm. 2017, 124, 901-905. [CrossRef]

44. Haaxma, C.A.; Bloem, B.R.; Borm, G.F.; Oyen, W.J.; Leenders, K.L.; Eshuis, S.; Booij, J.; Dluzen, D.E.; Horstink, M.W. Gender differences in Parkinson's disease. J. Neurol. Neurosurg. Psychiatry 2007, 78, 819-824. [CrossRef] [PubMed]

45. Martinez-Martin, P.; Pecurariu, C.F.; Odin, P.; Van Hilten, J.J.; Antonini, A.; Rojo-Abuin, J.M.; Borges, V.; Trenkwalder, C.; Aarsland, D.; Brooks, D.J. Gender-related differences in the burden of non-motor symptoms in Parkinson's disease. J. Neurol. 2012, 259, 1639-1647. [CrossRef] [PubMed]

46. Cholerton, B.; Johnson, C.O.; Fish, B.; Quinn, J.F.; Chung, K.A.; Peterson-Hiller, A.L.; Rosenthal, L.S.; Dawson, T.M.; Albert, M.S.; $\mathrm{Hu}$, S.-C. Sex differences in progression to mild cognitive impairment and dementia in Parkinson's disease. Parkinsonism Relat. Disord. 2018, 50, 29-36. [CrossRef] [PubMed]

47. Gillies, G.E.; Murray, H.E.; Dexter, D.; McArthur, S. Sex dimorphisms in the neuroprotective effects of estrogen in an animal model of Parkinson's disease. Pharmacol. Biochem. Behav. 2004, 78, 513-522. [CrossRef]

48. Buck, S.A.; Steinkellner, T.; Aslanoglou, D.; Villeneuve, M.; Bhatte, S.H.; Childers, V.C.; Rubin, S.A.; De Miranda, B.R.; O'Leary, E.I.; Neureiter, E.G.; et al. Vesicular glutamate transporter modulates sex differences in dopamine neuron vulnerability to age-related neurodegeneration. Aging Cell 2021, 20, e13365. [CrossRef]

49. Shin, J.W.; Shim, E.S.; Hwang, G.H.; Jung, H.S.; Park, J.H.; Sohn, N.W. Cell size-dependent Nogo-A expression in layer V pyramidal neurons of the rat primary somatosensory cortex. Neurosci. Lett. 2006, 394, 117-120. [CrossRef]

50. Jiang, W.; Xia, F.; Han, J.; Wang, J. Patterns of Nogo-A, NgR, and RhoA expression in the brain tissues of rats with focal cerebral infarction. Transl. Res. 2009, 154, 40-48. [CrossRef]

51. Nagamoto-Combs, K.; Morecraft, R.J.; Darling, W.G.; Combs, C.K. Long-term gliosis and molecular changes in the cervical spinal cord of the rhesus monkey after traumatic brain injury. J. Neurotrauma. 2010, 27, 565-585. [CrossRef] [PubMed]

52. Theotokis, P.; Lourbopoulos, A.; Touloumi, O.; Lagoudaki, R.; Kofidou, E.; Nousiopoulou, E.; Poulatsidou, K.N.; Kesidou, E.; Tascos, N.; Spandou, E.; et al. Time course and spatial profile of Nogo-A expression in experimental autoimmune encephalomyelitis in C57BL/ 6 mice. J. Neuropathol. Exp. Neurol. 2012, 71, 907-920. [CrossRef] [PubMed]

53. Liechti, R.; Ducray, A.D.; Jensen, P.; Di Santo, S.; Seiler, S.; Jensen, C.H.; Meyer, M.; Widmer, H.R. Characterization of fetal antigen 1/delta-like 1 homologue expressing cells in the rat nigrostriatal system: Effects of a unilateral 6-hydroxydopamine lesion. PLoS ONE 2015, 10, e0116088. [CrossRef]

54. Seiler, S.; Di Santo, S.; Andereggen, L.; Widmer, H.R. Antagonization of the Nogo-Receptor 1 Enhances Dopaminergic Fiber Outgrowth of Transplants in a Rat Model of Parkinson's Disease. Front. Cell. Neurosci. 2017, 11, 151. [CrossRef] [PubMed] 